\title{
Redefining Static and Dynamic Spaces Genius integration in Historic Cairo
}

\author{
Aly Mohamed El Husseiny ${ }^{1}$, Ahmed Aly El Husseiny ${ }^{2}$ \\ ${ }^{1}$ Architecture Dept., Faculty of Engineering, University of Minia, Minia 61519, Egypt \\ ${ }^{2}$ Architecture Dept., Faculty of Engineering, CairoUniversity, Cairo 12613, Egypt
}

alhusseiny14@yahoo.com

\begin{abstract}
Streets of Historic Cairo are the main essence to constitute a significant community that is reputable by intimacy and provides a pleasure to walk in urban spaces. The monumental town which remained consistent hundreds of years is now seriously threatened by its rapid socio-cultural change. The degree of enclosure, thickness of walls, wideness of openings in the space boundaries, and the nature of activities are all factors to assure either the static or dynamic state of an urban space. An observation study aims to discover how genius is integration of variations of static and dynamic spaces suits behavioral needs.
\end{abstract}

Keywords: Open space; urban space; static and dynamic spaces; Historic Cairo.

eISSN 2398-4295 @ 2018. The Authors. Published for AMER ABRA cE-Bs by e-International Publishing House, Ltd., UK. This is an open-access article under the CC BY-NC-ND license (http://creativecommons.org/licenses/bync-nd/4.0/). Peer-review under responsibility of AMER (Association of Malaysian Environment-Behaviour Researchers), ABRA (Association of Behavioural Researchers on Asians) and cE-Bs (Centre for EnvironmentBehaviour Studies), Faculty of Architecture, Planning \& Surveying, Universiti Teknologi MARA, Malaysia.

DOI: http://dx.doi.org/10.21834/ajbes.v3i9.71 


\subsection{Introduction}

The distinct context of Historic Cairo is a result of an interactive life between man and a distinctive urban pattern. The built environment till beginning of the nineties of the last century had not changed in spaces' proportions or spirit for hundreds of years. Man and environment are both subject to change due to lately public and official actions.

This paper tries to record the unique spirit of El Darb el Ahmar by analyzing and understanding one of the human behavior mechanisms interacting with the built environment configuration. The paper focuses on the genius integration of static and dynamic spaces of the context, which according to the authors is an essential factor characterizing the area's spirit. The way integration of static and dynamic spaces that works in the case of Historic Cairo is not that easy to understand; also it is a big loss not to understand what makes its spaces distinct.

\subsection{Methodology}

Annual study trips of architecture students since 2004 helped providing appropriate photography to use in for the purpose of this paper. Moving in groups usually meets acceptance of people to photography than suspicious individuals carrying cameras in streets. Static and dynamic spaces when aesthetically addressed as basic proportional analysis of spaces and visual sequence, observation might be an adequate method for previous studies. But this study required much more interpretation of feelings and motivations of behavior patterns. Thus a deeper understanding of life style and communication with people, which cannot be gained by passing visits could be covered by the authors' ethnographic knowledge of the residential context. Being born in the area and having social connections for decades, the authors could follow up social alterations. Physical alterations could be noticed through photography comparison through yearly visits. Moreover, the authors retrieved self-findings of previous investigations of territoriality to discuss the paper's concerns.

\subsection{Redefining Principles of Static and Dynamic Spaces}

Static and dynamic spaces have had little attention in the vocabulary of urban design. Many writers have briefly described them as spacious and linear spaces, as in a GLC study (1978). Frederick (2007) stated that geometric shapes have inherent dynamic qualities that influence one's perception and experience of the built environment. Openness, enclosure; links, nodes; squares and streets; are urban fabric components that referred to distinguish spaces that may express visual sequences of 'static and dynamic' in a city. The term dynamic is about movement. Since most activities in general can be distinguished in terms of moving or staying, the paper supposes that similarly the conforming space whether being static or dynamic is a critical configuration. When harmony occurs between what a space offers and a user needs, the space where the activity occurs then is a successful one.

The paper argues that direct understanding that when a space tends to be squared it is in that case a static one, while when it tends to be linear it is then dynamic can be a simplistic 
one. The paper aims to review this basic fact not to criticize it, but to deepen the understanding of circumstances that make stasis and dynamism qualitatively ranging and complicated. The following factors are to be considered:
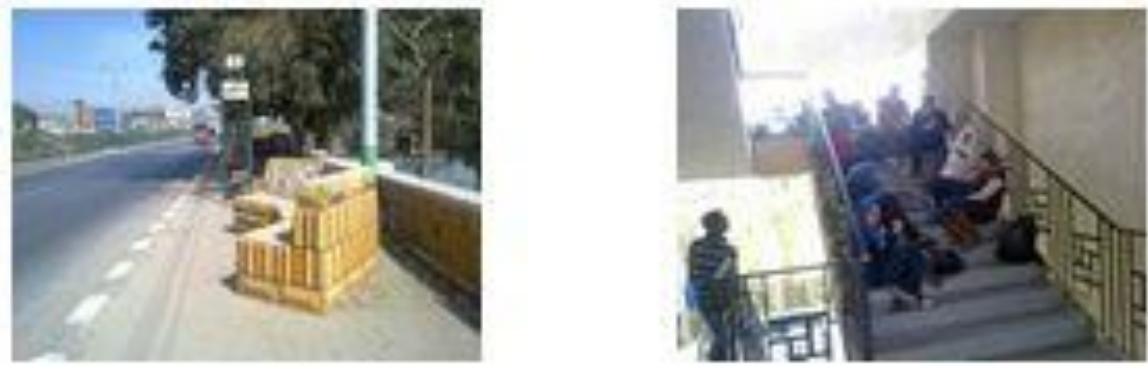

Fig. 1. (a) A built seat designed to sit on a sidewalk of a traffic road of Minia -Aswan shows how much a discomfort it is to provide a static activity in a totally dynamic milieu; source: the authors, (2011); While in (b) staircases that are supposed to be dynamic afforded a static space for students to sit since it's located in the top floor; source: the authors, (2011).

\subsection{Plan proportions:}

Talking about plan proportions, Fredrick (2007) stated that a square is inherently static and non directional. Consequently, a room of square or cubic proportions may feel restful. A rectangle, because it has two long sides and two shorter sides, is inherently directional. The longer a rectangular room is, the more it will stimulate visual and physical movement parallel to its long axis.

\subsection{Height of boundaries:}

A key factor defining a space is how the edge can be perceived. While a squared space is inviting to sit or to stay in, we cannot ignore how the edge walls will confirm the shape of the ground. The wall is a tool of protection that man would like to use to protect his back. The more the walls enclose a space, the more feeling of stability occurs.

\subsection{Wall thickness and visual transmittance:}

Walls mostly define the space proportions but not necessarily enclose a space. Enclosure is subject of change due to the ability of seeing through the wall to open scenes. Therefore, the style of openings and how wide they are, present an effective factor of stasis as well as the degree of the walls' opacity and transparency of openings.

\subsection{Floor patterns:}

Lateral lines pavements play visual effects that may help slow down moving in linear paths like. For instance, a mall corridor one would provide more chances to watch display windows. On the other hand, longitudinal lines may encourage going forward. In general in the perspective, using vanishing lines with same direction of movement can be a hidden stimulus to move.

Roughness degree may be an additional significant factor on the degree of dynamism too. 


\subsection{Activity patterns:}

Activity is a vital component of urban space composition. In addition to its visual reconfiguration of a space proportions because of its physical presentation, it specifies the places characteristics and impression. Movement in a space is a determining factor of how dynamic is the space.

\subsection{Movement motivation:}

Moving has two types of motivation, either necessary or optional. Necessary moving is when one has to go to an obligatory commitment to do, like to work or to get food, while optional moving is targeting activities that can be postponed such as recreation, visiting a friend or pastime. Historic Cairo streets include the two types because of the mechanical traffic's retraction. Egyptians may mix both types in relative percentages according to the initial reason to walk out.
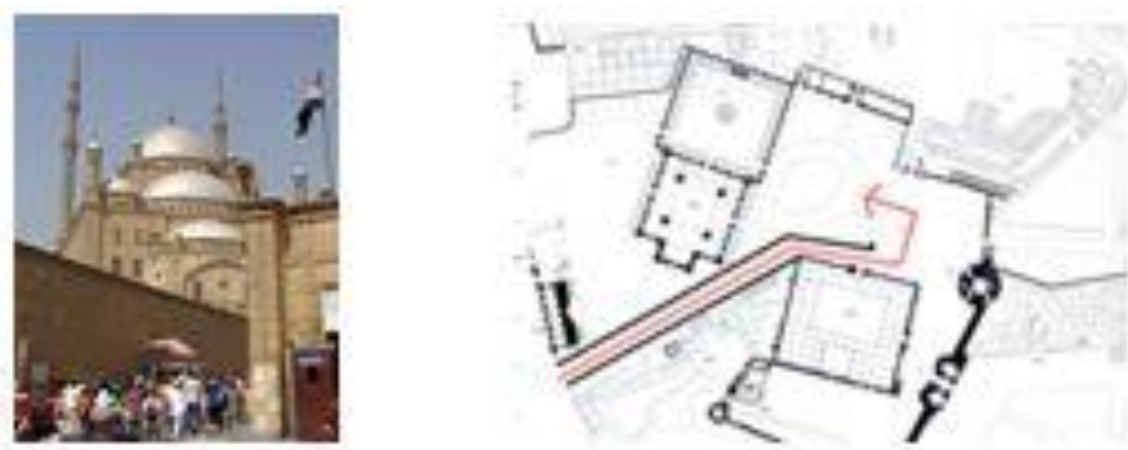

Fig.2. Exceptional experience of approaching the Mohamed Aly Mosque. The Mosque is partially seen in the beginning (a); source: Wikimedia, (2012); then moving in a dynamic corridor until reaching a spacious space to observe the entrance as shown in (b); source: reproduced from Warner, Nicholas. The monuments of Historic Cairo. American Research Centre in Egypt, (2005).

\subsection{Brilliance of sequential dynamic and static in Historic Cairo}

One cannot miss the unique, harmonious structure of spaces in the whole old city. The paper will demonstrate an example of the experience of approaching Mohamed Aly Mosque in the Salah El Din Citadel as a master urban experience. The mosque as the main item on the citadel hill has a fascinating way to approach. A dynamic space well confirmed by solid walls on both sides leads up to the entrance plaza. The linear path while exposes the walker to observe a part of the mosque, it deviates the movement direction away from it in a suspense strategy. After the observer's walk all the way of the corridor, he reaches a spacious, static space, leading up to the entrance, which is at this time behind him. At this point, the observer turns his body to allow remotely contemplating the monument before entering. 
The entrance of the mosque leads to the rear court of the mosque which sensitively presents a comfortable, static space welcoming after a long walk. A light arcade surrounds the court, and wall openings allow a static rest and a partial connection to the outside.

\subsection{Are Streets in Historic Cairo Dynamic?}

Historic streets in Cairo are mostly narrow linear extended paths, which usually described as dynamic spaces. The description is probably true when the linear space is simply a straight, uniform line, but this is not the case of the old district.

\subsection{Stasis of dynamic spaces and dynamism of static spaces:}

When observing streets' activities, one can monitor a place where the urban space encourages movement among many other things: standing, sitting, socializing, trading, and feeling intimacy. Along both sides of the dynamic roads, one can find consecutive static activities along the way. People may spend some time with a vendor who may be at the same time a neighbor or a friend. In the Egyptian culture, it may be often rude to ask for a need from someone close in a pragmatic way without introducing by a social talk first...
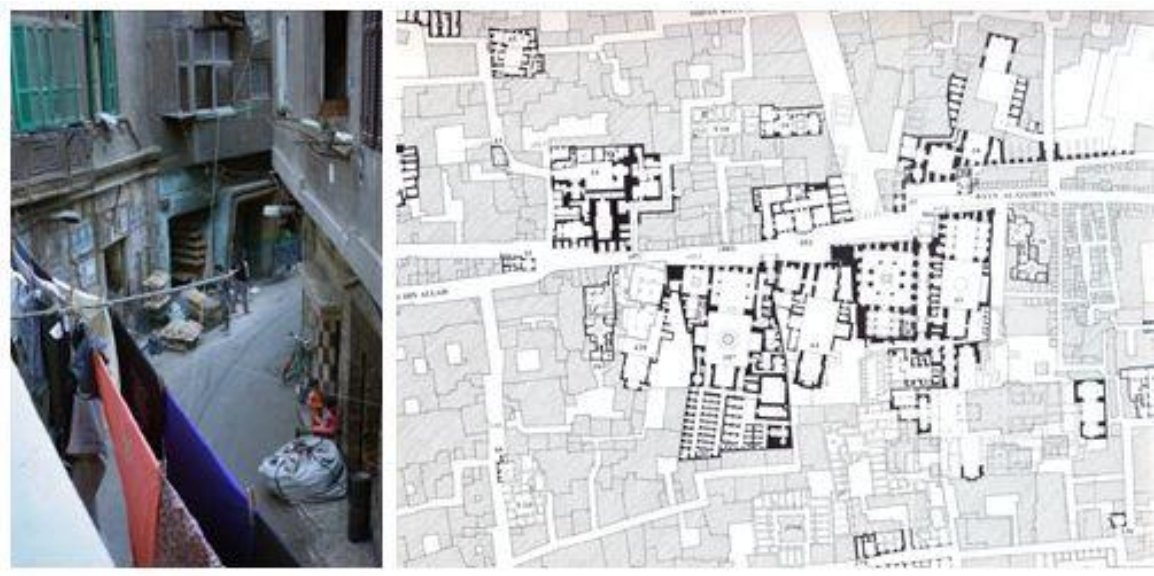

Fig.3. (a) Changing street direction and slight angulations of street space offer static clustering effects; source: the authors, (2012); (b) streets when changing width compose static spaces; source: Warner, Nicholas. The monuments of Historic Cairo. American Research Centre in Egypt, (2005).

\subsection{Segmentation of linear path decreases its dynamism.}

Numerous urban design, as early as the beginning of the sixties of the last century, have analyzed the segmentation of main paths of Historic Cairo, due to its fascinating visual sequences. Abou Seif (1970) studied closing views by vistas and sequential visual experiences of $A /$ Moez Street in details. The social and behavioral interest in the area had a little attention, but the author (1996) had pointed in a former study to the social and cultural 
outcomes of the streets' segmentation. The irregular deformation of the linear path causes a visual enclosure every few ten meters, which transforms a long, dynamic street into fragmented static spaces. Along the main paths almost every segment, vistas like mosques' minarets, or "sebils'(fountain buildings) are significant features. Virtual targets along a walk may eliminate fatigue and prevents tedious monotony. According to O'Sullivan \& Morrall (1996), psychological preferences affect the perception of the actual walking distance to be shorter than reality.
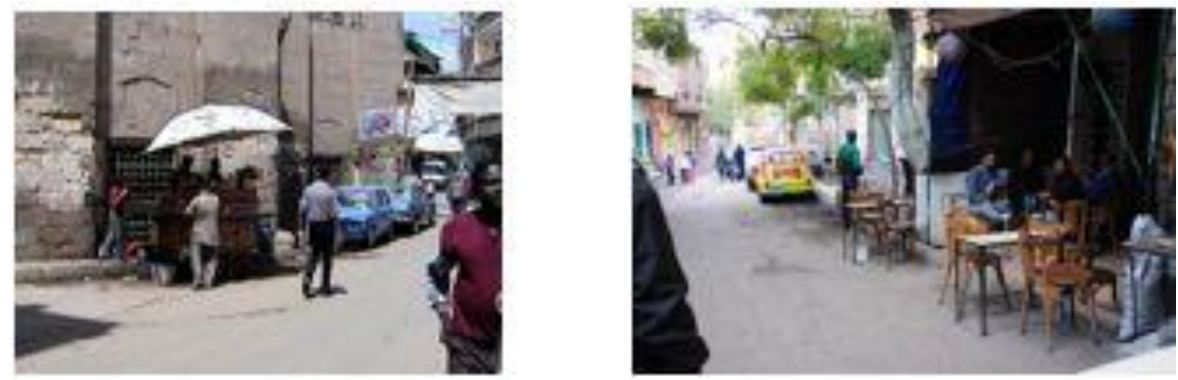

Fig.4. (a) a wide area of the street is used by a cart of a beans seller; source: the authors (2011); (b) and a cafe tentatively spilled out chairs in a public agreement; source: the authors (2011).
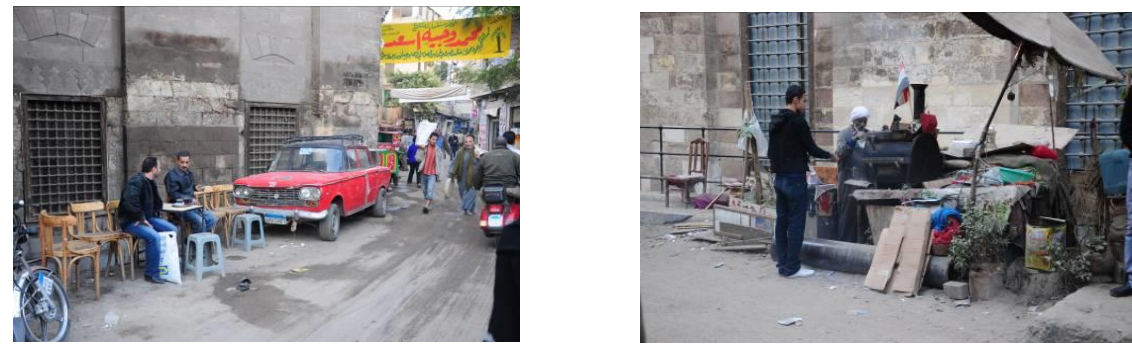

Fig.5. (a) using aside spaces' opportunity to create partial static spaces for settling temporal activity, or (b) for permanent activities to take place; source: the authors, (2011).

\subsection{Socio psychological assurance of segmentation stasis}

The genius continuity of overlaps of the sequential parts or defined spaces helps out to produce general coherence between residents along the district in a dynamic intersected chain of relationships. The transformation of the main dynamic space into smaller spaces transforms the street as a circulation mean into a residential stable area. Another fact that territorial feeling of what usually traditionally expressed in old districts as "my street" or "my district" increases due to the solid relationships and usual intensive visual and social contacts. The physical limits of territoriality turn the continuous path into smaller overlapped parts of "my street" along the roads that are limited by changing points of the movement 
directions or ending by a node or a small plaza (El Husseiny, 1994). Territorial stability then increases stasis of the physical enclosure of the road segments.

\subsection{Wideness Irregularity creates stasis}

. Random facades' ridges enhance the chances of observing a larger number of neighbors from any point on the path since one can see windows on the same side of the street. Buildings being not parallel, the wideness of spaces varies all the time. Widening spots in the street, when accompanies changing direction plays the role of nodes for their spacious distinction. All the mentioned deformations play a similar role of clustering in urban design with all its static characteristics despite its linear continuity.

\subsection{Behavioral Solutions of Creating Partial Static Spaces}

A linear deformed space of main corridors allows wideness and narrowness along the extended spine, in addition to the zigzagged form. John Simonds (1983), pointed out that pedestrian movement in a landscape is similar to streams of water. The water flow speed, increases in the middle, slows down at the sides, and may accumulate if side edges are somehow rough. Water and air dynamics are not distant from human movement. When the space alignment widens up, main stream of movement will continue in its direction leaving the widened area to be static. When a space does not afford a widened sector by its physical form, people often surpass the challenge by inventing static spaces. Putting barriers of unused objects has a competence to displace the pathway out of those sitting in the streets. It seems also that an interaction between private and public is a continuum relationship.
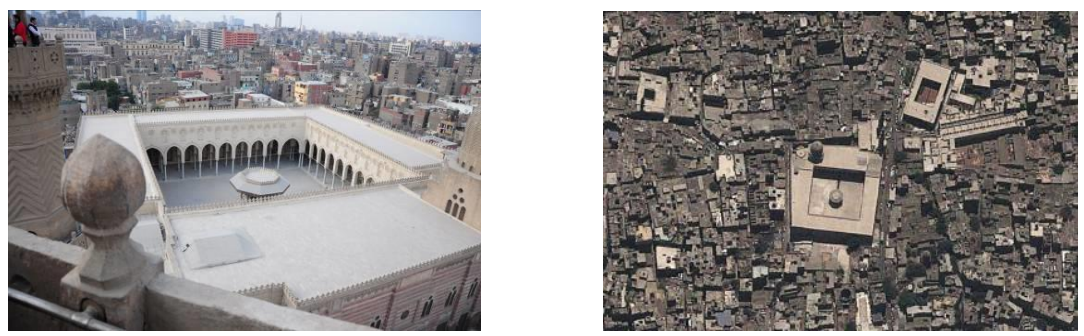

Fig.6. Linear dynamic spaces are usually contrasted by spacious static inner spaces of mosques and sometimes houses' courts almost demolished. (a) The Mo'aed Mosque's courtyard seen from its minerate; source: the authors, (2011); and (b) an aerial view for the context; source:

Google earth, (2011).

\subsection{Hidden Static Spaces in Historic Cairo}

Dynamic linear ridged paths, as the foremost constitute of streets, would be compensated by static spaces of the inner squared mosques' courts in the urban fabric. Feeling the contrast of spaces is a matter of movement experience. A spacious static space may be a comfortable 
place to stay in for anyone, but when perceiving it after a long walk experience, it is truly delightful (fig.6).

Although the mosques' courts are not the only static spaces in the urban tissue, they would be categorized as the top of spacious stasis in the organism, because of their uniform squaring shape, wall stones, and tight enclosure. Silence, birds' voices and planting may conduct stasis to perfection (fig.7). . Wide, static spaces in those mosques have a surprising perception of majesty that is compatible with security and stability. Other smaller mosques, like Al Merdany Mosque, planting courts add a superlative factor and add stability and quietness to their static mode.

Famous, historic houses in the area presented a paradigm of how static spaces of the internal court are a real feature to rest at home. Narrow streets approaching houses cannot make any anticipation for how large a house can be, which makes a real contradicting transition between dynamism and stasis. Stasis of the common residential space is not a result of physical proportions. Non physical aspects were more significant, such as the absence of passing through, and the territorial feeling of the residents towards the space. It seems that, controlling a space in ways, as providing privacy or territoriality, accentuates stasis of spaces. Being secured and leaving young children alone is an indicator of stasis. The case of grouping houses on a closed street is getting to disappear lately, since dense built alterations and social deconstruction of the neighboring system deteriorated such infallible integrations.

\subsection{Conclusion}

Numerous writings in urban design mentioned static and dynamic spaces in terms of visual perception. While preparing the papers' proposition, the authors intended to apply a descriptive observation method to examine how physical solutions have taken place to provide static spaces integrating the main dynamic space of streets. Once starting the field survey, the study tended to be more exploratory due to the complications and variability of spaces components. Observation has uncovered that physical configuration cannot be separate from human behavior and activity patterns. Being born and brought up in the old district, and following up the area's physical and social life for decades, supported in an ethnographic way the exploratory observation. Feelings of enclosures in segmental spaces of the residents, security in enclosed spaces, are issues that residents would not be uncovered without a deep bond with residents. The main finding of Stasis and dynamism of urban spaces is that it is not just a matter of physical setting, but it is rather a behavioral setting. In other words, it is about an interchangeable effect between man and space. A dynamic space may motivate to walk, while walking people bestow a dynamic spirit to a space. A space changes in a continuous state of modification to suit the patterns of activities, but a designer should understand how to motivate the process with minimal fabrication. 


\subsection{Learned information extracted from the observation study:}

- Static and dynamic is not equivalent to the enclosure and disclosure. Although enclosure may reinforce either stasis or dynamism in a protection sense, static or dynamic spaces would have different tastes and uses depending on their enclosure way and the nature of activity.

- Static space is not just a squared proportion space, but it is a matter of interactive human behavior with that physical setting. Stasis and dynamism may be considered a state of mind when using a space.

- None of the activities can be excluded from a classification as "static" or "dynamic". Static activity reciprocally needs a static space to occur, and dynamic activity suits a dynamic space.

- Spaces often can not be purely distinguished as Static or dynamic, but they may be proportionally overlapped at the expense of each other. A ranging scale of spaces can be assumed to be static at one extreme and dynamic at the other. Complicated factors may define how static or dynamic is a space between the two extremes.

- Integration of static and dynamic may be attained by creating a sequence of diversity of isolated spaces with different attributes, or by creating balanced diversity in a single space.

- A considered static space may be temporarily adjusted to include a dynamic activity, and vice versa, a general dynamic linear space may include static subspaces in order to make a space vital and restful at a time.

- Behavior adaptation, consciously or unconsciously, takes place to setup stasis or dynamism in a space to meet people's needs, either by furnishing barriers to create subspaces, or by forming spaces using corporal behavior.

\subsection{Key steps to activate the study findings}

In order to design a liveable environment, some key steps are strategic, and others are physical as follows:

\subsubsection{Strategic items may be as follows:}

- Socialization is not a time consuming; it is a matter of humanism flavor of a society.

- Searching for static spaces is the key for static activities to occur.

- Programming a static activity in an environment is a fundamental decision. It is a rational vision to make a place human.

- There is always a physical tool to create or cut a static space in the most dynamic environments.

- Integrating an associative static activity produces a humanistic flavor to an environment.

- Activity patterns are main components of a space.

- Privacy, security, and territoriality are significant providers of stasis in a space. 


\subsubsection{Functional and physical tools:}

Stasis and dynamism is not a two dimensional aspect. It can be affected by other physical factors according to given characteristics of a situation. Some of the tools are the following:

- A plan proportion is a main factor of determining a static or a dynamic space.

- Heights of boundaries, when increased, confirm either dynamism or stasis of a space.

- Solidity of boundaries materials (soft, hard, cool, warm) has a perceiving effect of the degree of enclosure.

- Permeability of walls and openings wideness decreases enclosure and add different tastes of stasis.

- Pavement patterns help assuring dynamism and stasis and may separate different uses of a common space.

- Barriers enclosing a space or a subspace for a purpose.

Future research can target understanding: how mixing static and dynamic spaces in other environments like open spaces, parks, schools' playfields can take place. Research may direct stasis and dynamism to be used to create livable indoor spaces too.
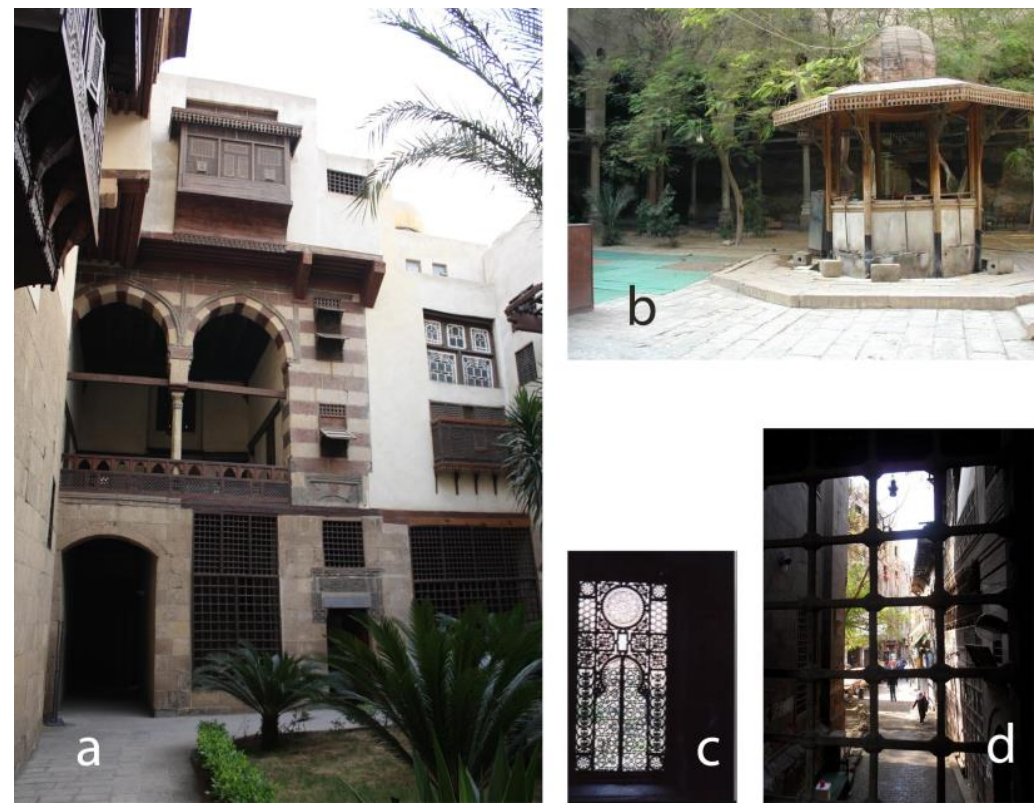

Fig.7. Courtyards in mosques and houses are real quiet places which accentuated stasis by contrasting the streets dynamism. Place silence, birds' voices, plants, and water fountains are all supporting stasis. (a) Static courtyard in Sehemi's house; source: the authors, (2009); (b) El Mardani Mosque's courtyard and fountain; source: the authors, (2006); (c) a window in El Refaie's Mosque; source: the authors,(2001); (d) window in Abou Hereba Mosque; (Source: the authors, (2008) water fountains). 


\section{References}

Abou Seif, Maher (1970). Design of urban spaces. M.Sc. Thesis. Faculty of Engineering. Cairo University.

El Husseiny, Aly (1994). Interaction of human behavior and open spaces. A dissertation to fulfil the doctoral degree in urban and city planning. University of Minia.

El Husseiny, Aly (1994). The impact of streets' pattern on territoriality feelings. A behavioural study of the Darb El Ahmar district, Old Cairo (Arabic). The proceedings of the $4^{\text {th }}$ Inetrnational Conference for Environmental Research. Towards a Better Environment. 1994. Nov 15-17. Ain shams University. Cairo.

El Husseiny, Aly (1996). Cultural preservation of Historic Cairo (Arabic). The proceedings of the 1st International Conference, Faculty of Engineering, Alexandria University. RETBE 96. Role of engineering towards better environment.1996. Dec 16-18. Alexandria. Egypt.

Frederick, Matthew (2007). 101 things I learned in architecture school. The MIT Press, Cambridge, Massachusetts, London, England.

Greater London Council (1978) An introduction to housing layout. A GLC study

MacCluskey, Jim (1979). Road form and townscape. The Architectural Press. London, 265-267.

O'Sullivan, Sean and Morrall, John (1996). Walking distances to and from Light-Rail transit stations. Transportation Research Record. Pedestrian and Bicycle Research. 1538. 19-26

Simonds, John Ormsbee (1983). Landscape architecture, a manual of site planning and design. McGraw-Hill, Inc.

Whyte, William (1980). Urban life of small urban spaces. The Conservation Foundation, Washington, D.C.

Warrner, Nicholas (2005). The monuments of Historic Cairo, a map and descriptive catalogue. An American Research Center in Egypt Edition, The American University In Cairo Press. Cairo, New York. 